\title{
Minimally invasive resection of lumbar intraspinal synovial cysts via a contralateral approach: review of 13 cases
}

\author{
Hamdi G. Sukkarieh, MD, Patrick W. Hitchon, MD, Olatilewa Awe, MD, and Jennifer Noeller, MSN \\ Department of Neurosurgery, University of lowa Carver College of Medicine, lowa City, lowa
}

OBJECT The authors sought to determine patient-related outcomes after minimally invasive surgical (MIS) lumbar intraspinal synovial cyst excision via a tubular working channel and a contralateral facet-sparing approach.

METHODS All the patients with a symptomatic lumbar intraspinal synovial cyst who underwent surgery at the University of lowa Hospitals and Clinics with an MIS excision via a contralateral approach were treated between July 2010 and August 2014. There was a total of 13 cases. Each patient was evaluated with preoperative neurological examinations, lumbar spine radiography, MRI, and visual analog scale (VAS) scores. The patients were evaluated postoperatively with neurological examinations and VAS and Macnab scores. The primary outcomes were improvement in VAS and Macnab scores. Secondary outcomes were average blood loss, hospital stay duration, and operative times.

RESULTS There were 5 males and 8 females. The mean age was 66 years, and the mean body mass index was 28.5 $\mathrm{kg} / \mathrm{m}^{2}$. Sixty-nine percent (9 of 13) of the cysts were at L4-5. Most patients had low-back pain and radicular pain, and one-third of them had Grade 1 spondylolisthesis. The mean $( \pm S D)$ follow-up duration was $20.8 \pm 16.9$ months. The mean Macnab score was $3.4 \pm 1.0$, and the VAS score decreased from 7.8 preoperatively to 2.9 postoperatively. The mean operative time was $123 \pm 30$ minutes, with a mean estimated blood loss of $44 \pm 29 \mathrm{ml}$. Hospital stay averaged 1.5 \pm 0.7 days. There were no complications noted in this series.

CONCLUSIONS The MIS excision of lumbar intraspinal synovial cysts via a contralateral approach offers excellent exposure to the cyst and spares the facet joint at the involved level, thus minimizing risk of instability, blood loss, operative time, and hospital stay. Prospective randomized trials with longer follow-up times and larger cohorts are needed to conclusively determine the superiority of the contralateral MIS approach over others, including open or ipsilateral minimally invasive surgery.

http://thejns.org/doi/abs/10.3171/2015.1.SPINE14996

KEY WORDS lumbar spine; synovial cysts; minimally invasive surgery; contralateral approach

0 YNOVIAL cysts of the spine are an unusual cause of nerve root and/or central canal compression. ${ }^{37}$ They arise, much like other synovial cysts in the body, from a rent in the capsule of degenerated facet joints (Fig. 1) accompanied by articular lining breakdown and encapsulated accumulation of fluid. ${ }^{20}$ These facet joints may also be filled with material from fibrinoid and myxoid degeneration, ${ }^{25}$ which may be associated with any degree of instability at that level. ${ }^{9,23,26}$ The prevalence of spondylolisthesis accompanying spinal levels with a synovial cyst ranges from $38 \%$ to $50 \% .6,25,41$ This occurrence was evident on MRI and CT scans of all lumbar facet joints associated with a synovial cyst in a radiographic study by Hsu et al. ${ }^{19}$

Lumbar intraspinal synovial cysts (LISCs) are not known to resolve spontaneously with conservative treatment; only 10 such cases have been reported in the literature. ${ }^{14,21,32,36,45}$ Despite being treated successfully by percutaneous imageguided aspiration and/or steroid injection, ${ }^{1,8,28}$ surgical resection remains a more definitive and permanent treatment, because injection techniques have not shown longterm benefits yet. Traditionally, the open technique for resecting these cysts would entail a midline approach with partial medial facetectomy in addition to possible partial

ABBREVIATIONS LISC = lumbar intraspinal synovial cyst; MIS = minimally invasive surgical; MISS = minimally invasive spine surgery; VAS = visual analog scale. SUBMITTED September 29, 2014. ACCEPTED January 13, 2015.

INCLUDE WHEN CITING Published online June 26, 2015; DOI: 10.3171/2015.1.SPINE14996.

DISCLOSURE The authors report no conflict of interest concerning the materials or methods used in this study or the findings specified in this paper. Dr. Hitchon is the recipient of research support from DePuy Spine and Medtronic Inc. for the Biomechanics Research Laboratory. No funds were received for the preparation of the manuscript. 


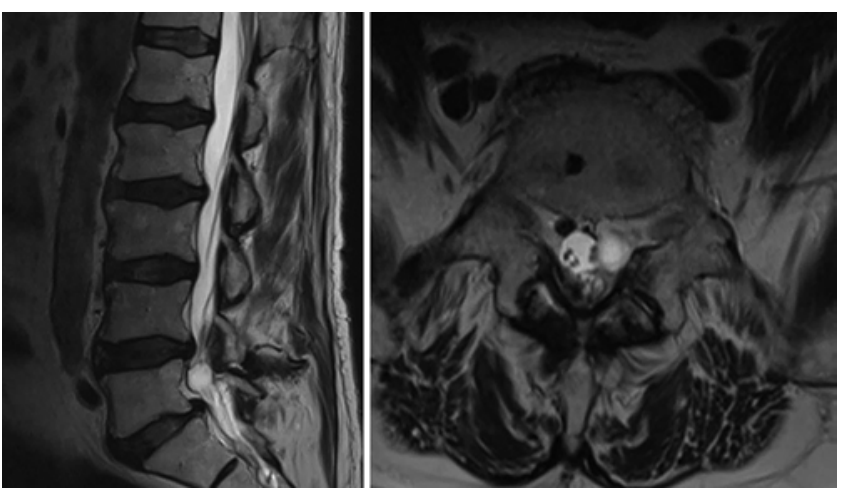

FIG. 1. Sagittal (left) and axial (right) T2-weighted MR images of the lumbar spine showing a large left-sided L4-5 facet joint synovial cyst.

laminectomies of the rostral and caudal laminae. ${ }^{12,13}$ This technique has been cited to cause postoperative spondylolisthesis, among other complications. ${ }^{16,19,30,40}$ Minimally invasive surgical (MIS) techniques for the resection of facet joint synovial cysts, whether ipsilateral ${ }^{41,42}$ or contralateral, ${ }^{22,38}$ have been described with good results.

The objective of this study was to evaluate our contralateral MIS approach regarding patient satisfaction ratings, functional outcome, blood loss, operative time, average hospital stay, and postoperative instability. We believe that this approach can provide results at least similar to those published for open or ipsilateral MIS techniques while preserving the integrity of the facet joint.

\section{Methods}

Between July 2010 and August 2014, 13 consecutive patients with a symptomatic LISC underwent MIS cyst resection through a contralateral tubular retractor approach at the University of Iowa Hospitals and Clinics. None of these patients had undergone surgery for spine pathology before. Each patient was evaluated preoperatively with physical and neurological examinations, dynamic radiographs of the lumbosacral spine (flexion and extension views), MR images of the lumbar spine, and determination of a visual analog scale (VAS) score. After surgery, each patient was followed up with clinic visits and telephone encounters. At each visit, in addition to a neurological examination, the VAS score was documented and imaging was ordered only if clinically indicated. Each patient underwent the operation by 1 surgeon (P.W.H.). In addition, patient satisfaction and postoperative return of functionality were documented with the Macnab scale ${ }^{31}$ as follows: a score of excellent indicates that all preoperative symptoms have been relieved and that the patient is able to carry out daily activities without any impairment; a score of good indicates minimum persistence of preoperative symptoms and that the patient is able to carry out daily activities without significant impairment; a score of fair indicates only partial relief of preoperative symptoms with limited physical activities; and a score of poor indicates unchanged or even worsened symptoms. These 4 categories were assigned numerical values, with 4 representing an excellent outcome and 1 representing a poor outcome. Furthermore, telephone calls were used to as- sess patient performance with the Macnab score even after formal clinic visits had stopped. The follow-up duration, operative time, blood loss, facet-level involvement, and hospital stay duration were also noted. The primary outcome was patient-reported satisfaction with the procedure as documented by the Macnab score. Secondary outcomes were operative time, blood loss, and hospital stay duration. Categorical variables were summarized by recording the number and percentage, whereas the continuous variables were summarized by recording the mean and the standard deviation (SD). In accordance with the US Code of Federal Regulations for the Protection of Human Subjects, institutional review board approval was obtained for this study.

\section{MIS Approach to LISCs}

As described by Awe and Hitchon, ${ }^{5}$ the patient is placed prone on a Jackson frame after general endotracheal intubation. Fluoroscopy is used to identify the correct level. The skin incision is planned to be horizontal, $15-30 \mathrm{~mm}$ lateral to the midline at the corresponding spinal level on the opposite side of the cyst. A series of tubular dilators are then used to penetrate the paraspinal muscles past the fascia and docked at the junction of the lamina and base of the spinous process. An 18- or 22-mm working channel is selected. The 22-mm channel is generally chosen for heavier patients in whom a longer tube $(80-100 \mathrm{~mm})$ is necessary. The working channel is then affixed in position by using a table-mounted arm. Through the microscope, the interlaminar space is enlarged by removing more of the caudal margin of the rostral lamina using a 3-mm power drill with the help of 2-mm and 3-mm bone punches. The ligamentum flavum is then excised, exposing the dural sac (Fig. 2). Most of the bone work with the drill is accomplished with the ligamentum flavum protecting the dura. With the dura depressed by a dissector or sucker, the ventral surface of the base of the spinous process and contralateral ligamentum flavum is excised, exposing the contralateral side of the canal (Fig. 3). With the thecal sac depressed, the cyst would usually come into view and can be, at times, quite adherent to the dura (Fig. 4). Care and patience are required to dissect the cyst from the dura without creating a tear in the dura. The cyst is freed circumferentially from the dura ventrally and from the facet joint from which it arises. Finally, it is grasped and completely excised (Fig. 5). It may not come away whole, and the cyst may be entered and partially collapsed, which facilitates its delivery. The gap that is left after the cyst is removed can also be appreciated (Fig. 6). The skin is closed with 4-0 Monocryl and Dermabond. The patient is mobilized the same day and may be discharged home the day of surgery.

\section{Results}

Patient demographic information is summarized in Table 1 . There were 13 patients ( 5 male, 8 female) in this series. The mean age $( \pm \mathrm{SD})$ was $66 \pm 11$ years. The average body mass index was $28.5 \pm 6 \mathrm{~kg} / \mathrm{m}^{2}$. Sixty-nine percent ( 9 of 13) of the patients had a synovial cyst at the L4-5 level, whereas the others had one at the L3-4 level. The most predominant symptom (54\%) was low-back pain in combination with radicular pain. Four (31\%) of the 13 


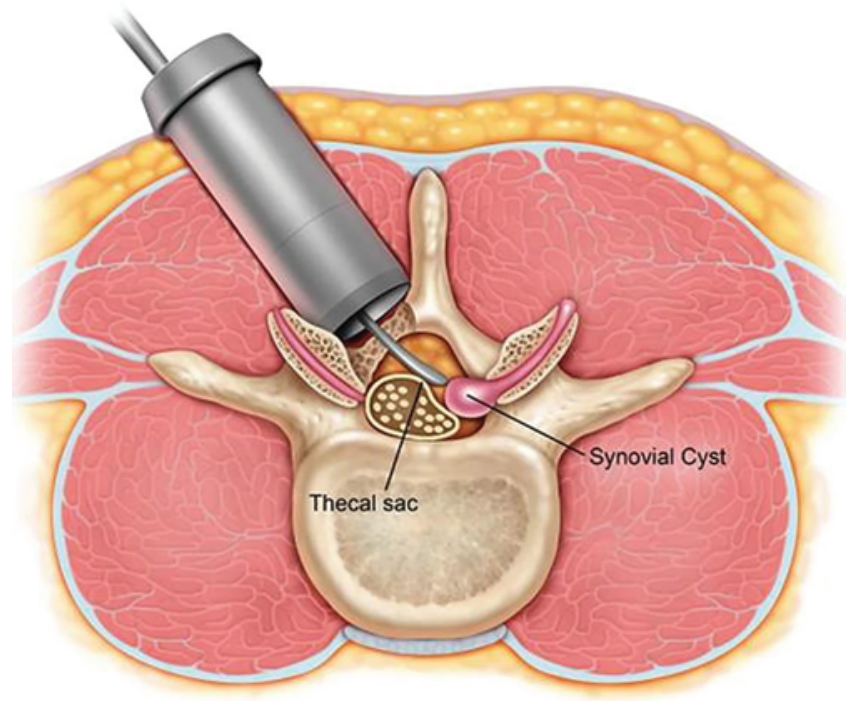

FIG. 2. Illustration showing MIS tube access to the synovial cyst via contralateral laminotomy. Copyright Patrick W. Hitchon. Published with permission. Figure is available in color online only.

patients had fixed Meyerding Grade 1 anterolisthesis ${ }^{27}$ that was not deemed (based on flexion/extension films) unstable enough to necessitate fusion. The patients were followed up for an average time of $20.8 \pm 16.9$ months (range 2-52 months).

Patient outcomes are presented in Table 2. The mean postoperative Macnab score was $3.4 \pm 1.0$, with an excellent outcome in 9 of the 13 patients and a good outcome in 1 patient. The mean VAS score decreased from 7.8 preoperatively to 2.9 postoperatively. The mean operative time was $123 \pm 30$ minutes, and the estimated blood loss was $44 \pm 29 \mathrm{ml}$. The mean length of hospital stay was $1.5 \pm$ 0.7 days. The 3 patients with persistent pain underwent repeat MRI examinations of the lumbar spine to check for residual cysts. Table 3 shows the preoperative and postoperative dimensions of the synovial cysts. Two patients were still symptomatic even after complete cyst excision. There were no complications, such as incidental durotomy, worsening of preoperative symptoms or infection, or the need for additional surgery encountered in this series. All the cysts in our series were pathologically confirmed to be true synovial cysts with the presence of synovial cell lining and xanthochromatic changes.

\section{Discussion}

LISCs remain a controversial topic with regard to the best treatment modality and approach. Not all synovial cysts described in the literature are related to instability. A minority of these cysts have reportedly been caused by trauma. ${ }^{15,24}$ Most people who suffer from a symptomatic facet joint synovial cyst have an age ranging from 28 to 94 years, with an average in the 60s..$^{19,30,48}$ There is no clear male or female predilection. ${ }^{19,30,33}$ Our results, with a mean patient age of $66 \pm 11$ years with 5 males and 8 females, are in agreement with those in the literature.

These cysts are typically found in the lumbar spine, especially at the L4-5 level, which bears the highest motion

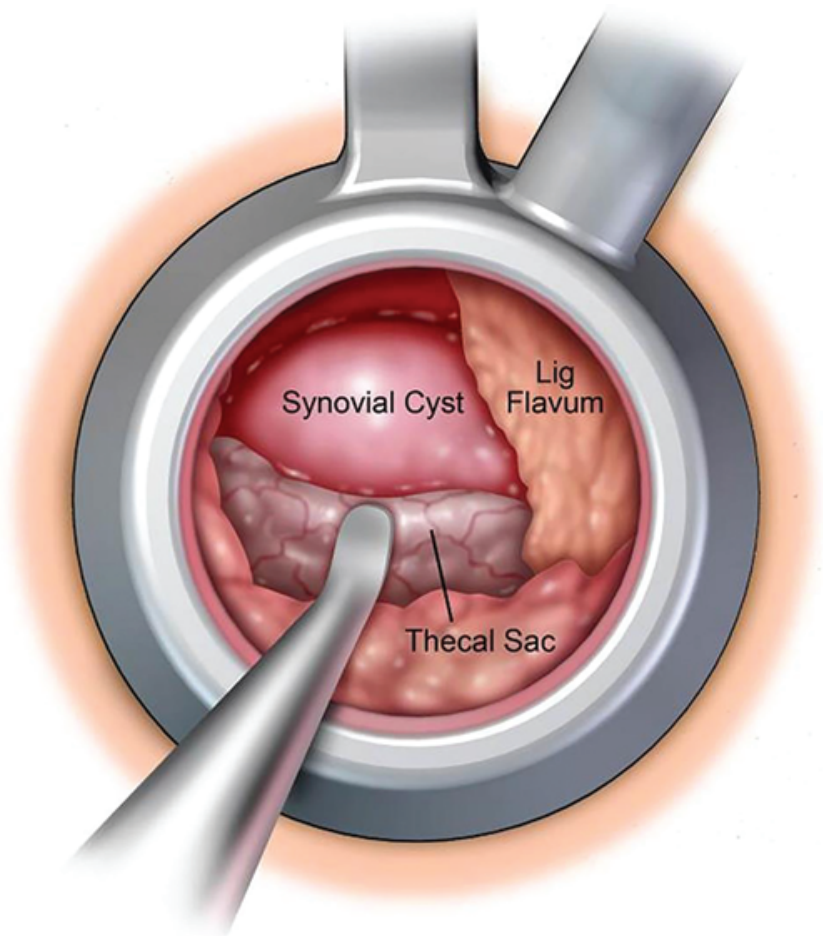

FIG. 3. Illustration showing the view from within the working channel. The plane between the thecal sac and the synovial cyst can be developed easily. Lig Flavum = ligamentum flavum. Copyright Patrick W. Hitchon. Published with permission. Figure is available in color online only.

in the lumbar region. ${ }^{3,19,29}$ It is highly uncommon for a facet joint synovial cyst to be found in the cervical or thoracic region. ${ }^{11,16,18,40}$ These cysts arise dorsolaterally within the canal and, as such, can compress traversing and/or exiting nerve roots and can cause overall stenosis at the involved level. $3,13,16,18$ They have also been reported to arise in the midline. ${ }^{35}$ Although facet joint synovial cysts are usually associated with radicular symptoms, they might also cause neurogenic claudication, especially in people with existing stenosis. ${ }^{18,19,30}$ Acute cauda equina syndrome may be the

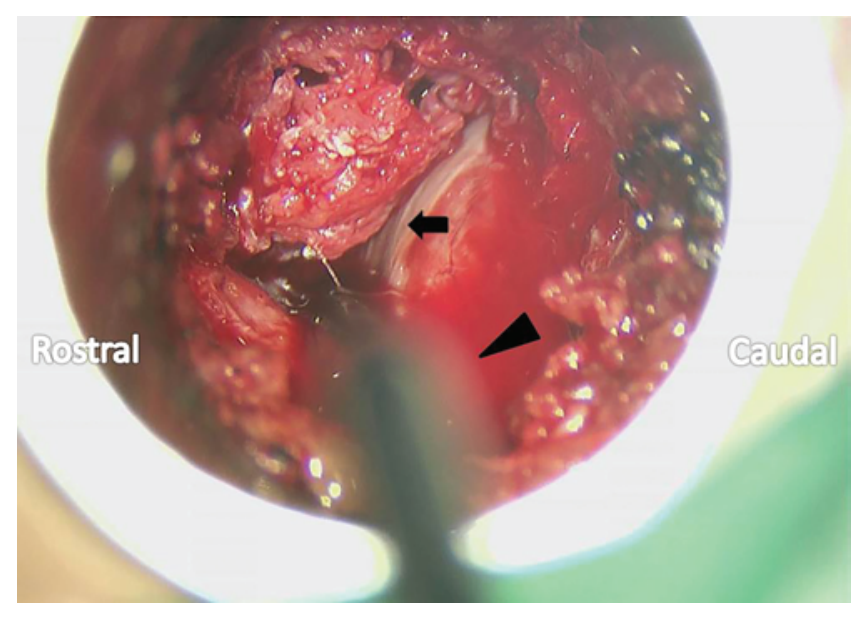

FIG. 4. Intraoperative photograph taken by the operating microscope. The synovial cyst (arrow) is being dissected from the thecal sac (arrowhead). Figure is available in color online only. 


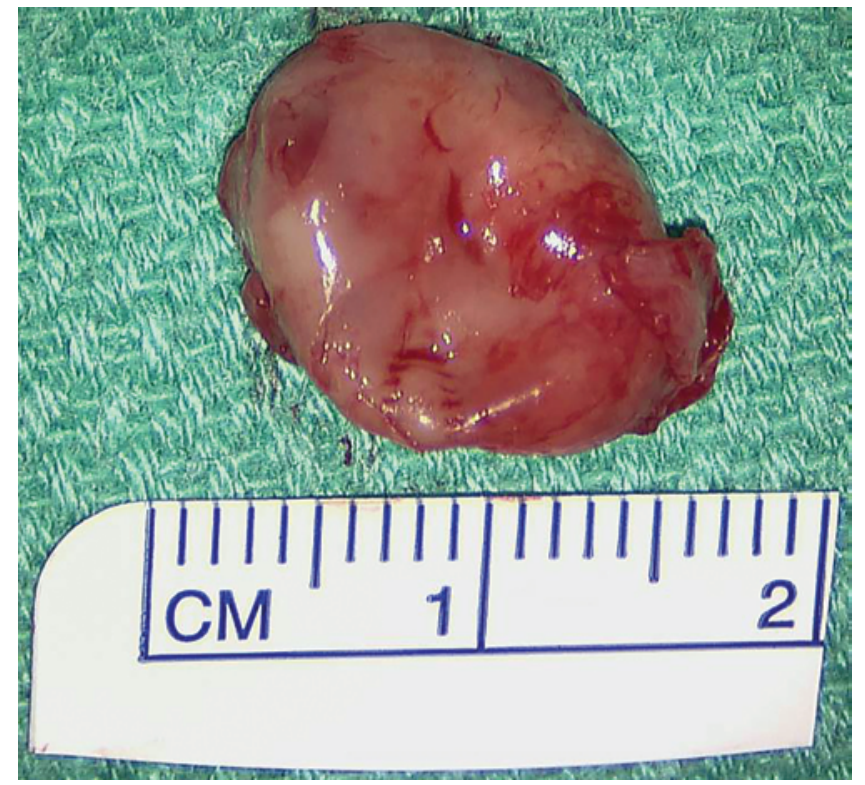

FIG. 5. Photograph of the synovial cyst after excision. Figure is available in color online only.

presenting sign of a lumbar intraspinal synovial cyst, with such reported cases after acute hemorrhage within these cysts. ${ }^{46}$ Lyons et al. ${ }^{30}$ reported that $13 \%$ of 194 patients with an LISC in their study presented with acute cauda equina syndrome. In our series, as well, almost $70 \%$ (9 of 13) of the patients had their synovial cyst at the L4-5 level and presented with low-back pain and radicular symptoms.

Although previously considered a rare entity, LISCs are being diagnosed more frequently through the use of MRI, and we have a better ability to radiologically differentiate these cysts from other intraspinal pathologies. ${ }^{2}$ Whereas pathologies such as herniated discs improve with conservative treatment, ${ }^{4}$ the more definitive treatment for an LISC is resection. Trummer et al. ${ }^{48}$ studied 19 patients with a symptomatic LISC who had undergone open surgical cyst excision and reported 17 excellent and 2 good

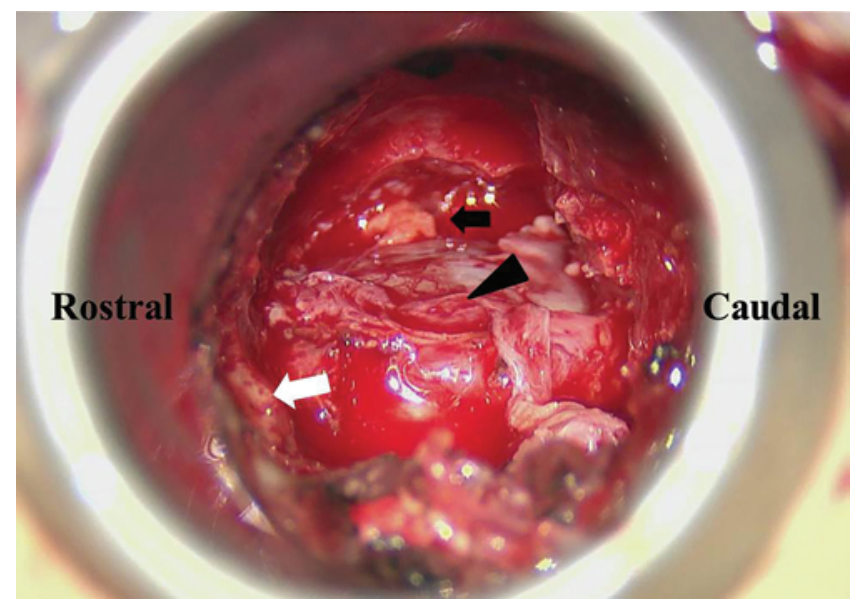

FIG. 6. Photograph taken with the operating microscope. The void (black arrow) left after cyst excision can be appreciated, as can the trailing edge of the lamina (white arrow) and the dural sac (black arrowhead). Figure is available in color online only.
TABLE 1. Patient demographics

\begin{tabular}{lc}
\hline \multicolumn{1}{c}{ Patient Characteristic } & Value \\
\hline Mean age $( \pm$ SD) $(\mathrm{yrs})$ & $66 \pm 11$ \\
\hline Gender (M/F) & $5 / 8$ \\
\hline Mean body mass index $\left( \pm\right.$ SD) $\left(\mathrm{kg} / \mathrm{m}^{2}\right)$ & $28.5 \pm 6$ \\
\hline Level of cyst (n/N [\%]) & $4 / 13(31)$ \\
\hline L3-L4 & $9 / 13(69)$ \\
\hline L4-L5 & \\
\hline Clinical symptoms (n/N [\%]) & $4 / 13(31)$ \\
\hline Radicular pain only & $0 / 13(0)$ \\
\hline Neurogenic claudication only & $7 / 13(54)$ \\
\hline Low-back/radicular pain & $2 / 13(15)$ \\
\hline Low-back pain/claudication & $20.8 \pm 16.9$ \\
\hline Mean follow-up ( \pm SD) (mos) & $4 / 13$ \\
\hline Spondylolisthesis (Grade 1, fixed slip) (n/N)
\end{tabular}

postoperative results at an average follow-up of 23 months. Lyons et al. ${ }^{30}$ retrospectively reviewed all cases of patients at the Mayo Clinic between 1974 and 1986 with an LISC that was treated with open excision; with at least 6 months of follow-up, $91 \%$ (134 of the 147 who had 6 months of follow-up data) of the patients had a good or excellent result. Image-guided aspiration and/or rupture techniques have not been very successful at maintaining a long-term benefit. Parlier-Cuau et al. ${ }^{34}$ showed that only one-third of the patients in their study responded favorably within 1-6 months to cyst steroid injection. Shah et al. ${ }^{44}$ found that, over a 50 -week follow-up period, only $10 \%$ of their patients had sustained pain relief after cyst aspiration and injection.

Before the advent of minimally invasive and tube surgery, synovial cysts were excised by laminectomy and facetectomy at the involved level in addition to fusion to prevent postoperative instability. ${ }^{23,40}$ Such extensive bone resection has been linked with postoperative spondylolisthesis at the involved levels, even those with no preoperative evidence of instability. ${ }^{40}$ The rates of late fusion surgery for spondylolisthesis incurred after open resection of an LISC have varied from 1.8 to $6 \% .^{6,7,30}$ As such, MIS techniques for the excision of LISCs have been developed. Conversely, Sehati et al. ${ }^{42}$ reviewed 19 patients with a symptomatic LISC who had undergone MIS cyst resection via an ipsilateral tubular retractor approach. They found that $95 \%$ of the patients reported an excellent or good result. The mean operative time was 158 minutes, and the mean blood loss was $31 \mathrm{ml}$. Two of the patients had a dural tear that was treated with primary closure. In spite of these favorable results with the ipsilateral MIS approach, the facet joint has to be violated, at least in part. Sandhu et al. ${ }^{41}$ showed a mean blood loss of $35 \mathrm{ml}$ (range 5-100 ml) and a mean operative time of 97 minutes (range 50-180 minutes) in 17 patients who had undergone MIS LISC excision (mean follow-up 13 months). Fourteen patients (82\%) had an excellent result, and 2 patients $(12 \%)$ had a good result according to the Macnab score. The only patient with a poor outcome had preoperative spondylolisthesis and underwent fusion 4 months after the cyst-excision surgery. 
TABLE 2. Outcome data*

\begin{tabular}{lc}
\hline \multicolumn{1}{c}{ Outcome } & Mean $( \pm$ SD) \\
\hline Macnab score & $3.4(1.0)$ \\
\hline VAS score & \\
\hline Preop & 7.8 \\
\hline Postop & 2.9 \\
\hline Operative time (mins) & $123(30)$ \\
\hline EBL (ml) & $44(29)$ \\
\hline Length of hospital stay (days) & $1.5(0.7)$ \\
\hline
\end{tabular}

$\mathrm{EBL}=$ estimated blood loss.

* There were no complications (e.g., incidental durotomy, postoperative CSF leak, infection, worsening of symptoms).

No instability was noted in the remaining 16 patients at follow-up.

The MIS contralateral approach for the excision of LISCs has been advocated over the ipsilateral approach because of its facet-sparing potential..$^{38}$ James et al. ${ }^{22}$ retrospectively reviewed 16 patients with an LISC who underwent MIS contralateral cyst excision and had a mean operative time of 105 minutes and blood loss of $<40 \mathrm{ml}$ in every case. At a median follow-up time of 18 months, 9 patients had an excellent outcome and 5 patients had a good outcome according to Macnab and VAS scores. Two patients were lost to follow-up. No instability was noted on last follow-up. Rhee et al.$^{38}$ described 2 patients with a LISC that was resected via an MIS contralateral approach. At their 1-year follow-up, the patients denied any residual pain, and their dynamic lumbar radiographs failed to show any evidence of instability.

Rates of lumbar cyst recurrence after open excision range from $1.3 \%$ to $10.8 \%$, and the rates of radiographic spondylolisthesis after excision range from $2 \%$ to $31 \% .{ }^{17}$ Ganau et al. ${ }^{17}$ reviewed the results of microscopic resection of LISCs in 17 patients. They closely examined the pathological results of the excised cysts, looking for true synovial cell lining, the intracystic presence of hemosiderin, and positive staining for cytokeratin immunostains, which are indicators of a synovial microtraumatic origin of the cysts. They aimed at differentiating cysts that would necessitate complete facetectomy (for risk of cyst recurrence) from other cystic lesions of the lumbar spine. Although all of the cysts in their series were actually true synovial cysts that were treated with hemilaminectomy/ laminectomy with facet sparing, none of these patients, even those with preoperatively fixed spondylolisthesis, presented with instability at a median follow-up of 28 months. Forty-six patients with a LISC treated with microscopic decompression were followed up for nearly 10 years by Weiner et al. ${ }^{49}$ The only indication for concomitant fusion (noninstrumented) in this series was the presence of spondylolisthesis, which was involved in $50 \%$ of their patient population. Even though the authors did not differentiate static from dynamic spondylolisthesis, $89 \%$ of the patients reported satisfaction with the surgery 10 years later, with no statistical differences for any outcome measure between patients who underwent fusion and those who did not. As such, the need for late surgery for postoperative instability might not be clinically significant. This
TABLE 3. Preoperative and postoperative MRI-determined cyst dimensions for patients with persistent pain

\begin{tabular}{cccc}
\hline \multirow{2}{*}{$\begin{array}{c}\text { Patient } \\
\text { No. }\end{array}$} & Spinal Level & Preop & Postop \\
\cline { 3 - 4 } & L4-5 & $8.5 \times 6.5 \times 15.5$ & $7.7 \times 7.1 \times 12.5$ \\
\hline 1 & L4-5 & $14.9 \times 6.0 \times 10.0$ & Complete excision \\
\hline 3 & L4-5 & $9.5 \times 8.6 \times 12.0$ & Complete excision \\
\hline * Dimension = anteroposterior length $\times$ width $\times$ height. &
\end{tabular}

observation was also seen in a Mayo Clinic experience with LISCs,$^{30}$ in which, of 194 patients who were treated with traditional open surgical decompression, only $2 \%$ developed late symptomatic spinal instability that required revision surgery and fusion after a minimum follow-up of 6 months (range 6-168 months).

Despite not being encountered in our series, incidental durotomy, whether during open or minimally invasive techniques, is a possible complication of synovial cyst resection secondary to cyst adherence to the dura. The risk of an inadvertent dural tear during spine surgery ranges from $1.6 \%$ to $17 \% .^{39,43,47}$ Factors that may increase the risk of a dural tear include accidental puncture of the dura with a surgical instrument, adherence of the dura to removed bone or cyst, and frailty of the dura after chronic compression. Although there have been many reports about managing dural tears that occur in open spine surgery, there have been only a few study reports that discussed the treatment of durotomy in minimally invasive spine surgery (MISS). The advantages of MISS with regard to dural tears is the smaller incisions with muscle-splitting dissections that create very small potential spaces for CSF accumulation/ leak or CSF fistulas. The disadvantages are the technical difficulties associated with attempts at primary closure of the dural tear through a narrow tubular corridor. Ruban and $\mathrm{O}^{\prime}$ Toole $^{39}$ treated 53 dural tears (9.4\%) in 563 patients who underwent MISS with a combination of primary repair via specially designed instruments and/or fibrin glue and Gelfoam pledgets, with bed rest only overnight followed by early mobilization, and the patients experienced no delayed complications. Early mobilization was reported by other studies of MISS complicated by durotomy as well, also with no delayed complications..$^{43,47}$ Chou et al. ${ }^{10}$ and $\mathrm{Wu}$ et al. ${ }^{50}$ also described treatment of dural tears during MISS with direct repair, fibrin glue, and bed rest with no need for reoperation.

Our results are very similar to those of previously reported studies. The Macnab and VAS scores show overall good and excellent symptom and functional improvement, with a mean operative time of $123 \pm 30$ minutes and an estimated blood loss of $44 \pm 29 \mathrm{ml}$. The mean length of hospital stay ( $1.5 \pm 0.7$ days) indicates that most patients were discharged the morning after their surgery. The patients encountered no intraoperative complications (i.e., no durotomy, worsening of preoperative symptoms or infection, or need for additional surgery).

Several possible limitations in this study have to be taken into consideration. First, this study was a retrospective case review and analysis with a relatively small number of patients and no randomized control (open or ipsilateral 
minimally invasive surgery) group. However, based on our limited experience, we believe that the contralateral approach enables cyst excision while sparing the facets. Second, the relatively short follow-up period of only 20.8 \pm 16.9 months and the unavailability of follow-up imaging for every patient make drawing conclusions on the presence or absence of postoperative iatrogenic instability and recurrence not feasible.

\section{Conclusions}

The contralateral MIS approach to LISC excision provides excellent surgical exposure, facet-sparing expeditious excision of the cyst, and minimal soft-tissue injury with low intraoperative and postoperative morbidity. Obviously, a more definitive statement on the advantages of the contralateral MIS approach compared with those of other approaches would require a randomized prospective study. The relative rarity of this condition makes this possibility unlikely.

\section{Acknowledgment}

We thank Faith Vaughn for her indispensable assistance in the preparation of this manuscript.

\section{References}

1. Amoretti N, Huwart L, Foti P, Boileau P, Amoretti ME, Pellegrin A, et al: Symptomatic lumbar facet joint cysts treated by CT-guided intracystic and intra-articular steroid injections. Eur Radiol 22:2836-2840, 2012

2. Apostolaki E, Davies AM, Evans N, Cassar-Pullicino VN: MR imaging of lumbar facet joint synovial cysts. Eur Radiol 10:615-623, 2000

3. Artico M, Cervoni L, Carloia S, Stevanato G, Mastantuono M, Nucci F: Synovial cysts: clinical and neuroradiological aspects. Acta Neurochir (Wien) 139:176-181, 1997

4. Asghar FA, Hilibrand AS: The impact of the Spine Patient Outcomes Research Trial (SPORT) results on orthopaedic practice. J Am Acad Orthop Surg 20:160-166, 2012

5. Awe O, Hitchon PW: Minimally invasive surgery for lumbar synovial cysts. Contemporary Neurosurgery 35:1-6, 2013

6. Banning CS, Thorell WE, Leibrock LG: Patient outcome after resection of lumbar juxtafacet cysts. Spine (Phila Pa 1976) 26:969-972, 2001

7. Boviatsis EJ, Stavrinou LC, Kouyialis AT, Gavra MM, Stavrinou PC, Themistokleous M, et al: Spinal synovial cysts: pathogenesis, diagnosis and surgical treatment in a series of seven cases and literature review. Eur Spine J 17:831-837, 2008

8. Bureau NJ, Kaplan PA, Dussault RG: Lumbar facet joint synovial cyst: percutaneous treatment with steroid injections and distention-clinical and imaging follow-up in 12 patients. Radiology 221:179-185, 2001

9. Bydon A, Xu R, Parker SL, McGirt MJ, Bydon M, Gokaslan ZL, et al: Recurrent back and leg pain and cyst reformation after surgical resection of spinal synovial cysts: systematic review of reported postoperative outcomes. Spine J 10:820826,2010

10. Chou D, Wang VY, Khan AS: Primary dural repair during minimally invasive microdiscectomy using standard operating room instruments. Neurosurgery 64 (5 Suppl 2):356359, 2009

11. Cohen-Gadol AA, White JB, Lynch JJ, Miller GM, Krauss WE: Synovial cysts of the thoracic spine. J Neurosurg Spine 1:52-57, 2004

12. Deinsberger R, Kinn E, Ungersböck K: Microsurgical treat- ment of juxta facet cysts of the lumbar spine. J Spinal Disord Tech 19:155-160, 2006

13. Epstein NE: Lumbar synovial cysts: a review of diagnosis, surgical management, and outcome assessment. J Spinal Disord Tech 17:321-325, 2004

14. Ewald C, Kalff R: Resolution of a synovial cyst of the lumbar spine without surgical therapy - a case report. Zentralbl Neurochir 66:147-151, 2005

15. Franck JI, King RB, Petro GR, Kanzer MD: A posttraumatic lumbar spinal synovial cyst. Case report. J Neurosurg 66:293-296, 1987

16. Freidberg SR, Fellows T, Thomas CB, Mancall AC: Experience with symptomatic spinal epidural cysts. Neurosurgery 34:989-993, 1994

17. Ganau M, Ennas F, Bellisano G, Ganau L, Ambu R, Faa G, et al: Synovial cysts of the lumbar spine-pathological considerations and surgical strategy. Neurol Med Chir (Tokyo) 53:95-102, 2013

18. Howington JU, Connolly ES, Voorhies RM: Intraspinal synovial cysts: 10-year experience at the Ochsner Clinic. J Neurosurg 91 (2 Suppl):193-199, 1999

19. Hsu KY, Zucherman JF, Shea WJ, Jeffrey RA: Lumbar intraspinal synovial and ganglion cysts (facet cysts). Ten-year experience in evaluation and treatment. Spine (Phila Pa 1976) 20:80-89, 1995

20. Indar R, Tsiridis E, Morgan M, Aldham CH, Hussein AA: Intraspinal lumbar synovial cysts: diagnosis and surgical management. Surgeon 2:141-144, 2004

21. Jackson DE Jr, Atlas SW, Mani JR, Norman D: Intraspinal synovial cysts: MR imaging. Radiology 170:527-530, 1989

22. James A, Laufer I, Parikh K, Nagineni VV, Saleh TO, Härtl $\mathrm{R}$ : Lumbar juxtafacet cyst resection: the facet sparing contralateral minimally invasive surgical approach. J Spinal Disord Tech 25:E13-E17, 2012

23. Khan AM, Girardi F: Spinal lumbar synovial cysts. Diagnosis and management challenge. Eur Spine J 15:1176-1182, 2006

24. Kono H, Nakamura H, Seki M, Hosomi R, Hara Y: Lumbar juxta-facet cyst after trauma. J Clin Neurosci 13:694-696, 2006

25. Kusakabe T, Kasama F, Aizawa T, Sato T, Kokubun S: Facet cyst in the lumbar spine: radiological and histopathological findings and possible pathogenesis. J Neurosurg Spine 5:398-403, 2006

26. Landi A, Marotta N, Tarantino R, Ruggeri AG, Cappelletti M, Ramieri A, et al: Microsurgical excision without fusion as a safe option for resection of synovial cyst of the lumbar spine: long-term follow-up in mono-institutional experience. Neurosurg Rev 35:245-253, 2012

27. Li Y, Hresko MT: Radiographic analysis of spondylolisthesis and sagittal spinopelvic deformity. J Am Acad Orthop Surg 20:194-205, 2012

28. Lim AK, Higgins SJ, Saifuddin A, Lehovsky J: Symptomatic lumbar synovial cyst: management with direct CT-guided puncture and steroid injection. Clin Radiol 56:990-993, 2001

29. Liu SS, Williams KD, Drayer BP, Spetzler RF, Sonntag VK: Synovial cysts of the lumbosacral spine: diagnosis by MR imaging. AJR Am J Roentgenol 154:163-166, 1990

30. Lyons MK, Atkinson JL, Wharen RE, Deen HG, Zimmerman RS, Lemens SM: Surgical evaluation and management of lumbar synovial cysts: the Mayo Clinic experience. J Neurosurg 93 (1 Suppl):53-57, 2000

31. Macnab I: Negative disc exploration. An analysis of the causes of nerve-root involvement in sixty-eight patients. J Bone Joint Surg Am 53:891-903, 1971

32. Mercader J, Muñoz Gomez J, Cardenal C: Intraspinal synovial cyst: diagnosis by CT. Follow-up and spontaneous remission. Neuroradiology 27:346-348, 1985 
33. Onofrio BM, Mih AD: Synovial cysts of the spine. Neurosurgery 22:642-647, 1988

34. Parlier-Cuau C, Wybier M, Nizard R, Champsaur P, Le Hir P, Laredo JD: Symptomatic lumbar facet joint synovial cysts: clinical assessment of facet joint steroid injection after 1 and 6 months and long-term follow-up in 30 patients. Radiology 210:509-513, 1999

35. Pindrik J, Macki M, Bydon M, Maleki Z, Bydon A: Midline synovial and ganglion cysts causing neurogenic claudication. World J Clin Cases 1:285-289, 2013

36. Pulhorn H, Murphy M: Spontaneous resolution of a symptomatic synovial cyst of the lumbar spine. Br J Neurosurg 26:123-124, 2012

37. Radatz M, Jakubowski J, Cooper J, Powell T: Synovial cysts of the lumbar spine: a review. Br J Neurosurg 11:520-524, 1997

38. Rhee J, Anaizi AN, Sandhu FA, Voyadzis JM: Minimally invasive resection of lumbar synovial cysts from a contralateral approach. J Neurosurg Spine 17:453-458, 2012

39. Ruban D, O'Toole JE: Management of incidental durotomy in minimally invasive spine surgery. Neurosurg Focus 31(4):E15, 2011

40. Sabo RA, Tracy PT, Weinger JM: A series of 60 juxtafacet cysts: clinical presentation, the role of spinal instability, and treatment. J Neurosurg 85:560-565, 1996

41. Sandhu FA, Santiago P, Fessler RG, Palmer S: Minimally invasive surgical treatment of lumbar synovial cysts. Neurosurgery 54:107-112, 2004

42. Sehati N, Khoo LT, Holly LT: Treatment of lumbar synovial cysts using minimally invasive surgical techniques. Neurosurg Focus 20(3):E2, 2006

43. Senker W, Meznik C, Avian A, Berghold A: The frequency of accidental dural tears in minimally invasive spinal fusion techniques. J Neurol Surg A Cent Eur Neurosurg 74:373377,2013

44. Shah RV, Lutz GE: Lumbar intraspinal synovial cysts: conservative management and review of the world's literature. Spine J 3:479-488, 2003
45. Swartz PG, Murtagh FR: Spontaneous resolution of an intraspinal synovial cyst. AJNR Am J Neuroradiol 24:12611263,2003

46. Tatter SB, Cosgrove GR: Hemorrhage into a lumbar synovial cyst causing an acute cauda equina syndrome. Case report. J Neurosurg 81:449-452, 1994

47. Than KD, Wang AC, Etame AB, La Marca F, Park P: Postoperative management of incidental durotomy in minimally invasive lumbar spinal surgery. Minim Invasive Neurosurg 51:263-266, 2008

48. Trummer M, Flaschka G, Tillich M, Homann CN, Unger F, Eustacchio S: Diagnosis and surgical management of intraspinal synovial cysts: report of 19 cases. J Neurol Neurosurg Psychiatry 70:74-77, 2001

49. Weiner BK, Torretti J, Stauff M: Microdecompression for lumbar synovial cysts: an independent assessment of long term outcomes. J Orthop Surg 2:5, 2007

50. Wu X, Zhuang S, Mao Z, Chen H: Microendoscopic discectomy for lumbar disc herniation: surgical technique and outcome in 873 consecutive cases. Spine (Phila Pa 1976) 31:2689-2694, 2006

\section{Author Contributions}

Conception and design: Hitchon, Sukkarieh. Acquisition of data: Hitchon, Noeller. Analysis and interpretation of data: Sukkarieh. Drafting the article: Sukkarieh, Awe. Critically revising the article: Hitchon, Sukkarieh. Reviewed submitted version of manuscript: all authors. Approved the final version of the manuscript on behalf of all authors: Hitchon. Statistical analysis: Sukkarieh. Study supervision: Hitchon.

\section{Correspondence}

Patrick W. Hitchon, Department of Neurosurgery, University of Iowa Carver College of Medicine, 200 Hawkins Dr., Iowa City, IA 52242. email: patrick-hitchon@uiowa.edu. 